\title{
Development and Validation of a Fashion Readiness Scale: A Preliminary Report
}

\author{
Cheng-Chieh Hsiao and Fang-Mei Liu
}

\begin{abstract}
Recently, fashion marketers have implemented marketing strategies like fast fashion and luxury democratization. These strategies make the global fashion market more dynamic and uncertain. In order to predict a consumer's purchase decision on fashion products, prior research has proposed a number of fashion-related concepts. However, most concepts focus only on the cognitive aspect of consumers' fashion responses, and existing scales for measuring these concepts are not multidimensional. To address these issues, this study attempts to (1) propose a concept of fashion readiness which captures a consumer's propensity to embrace new fashion and (2) develop a multidimensional scale for assessing fashion readiness. After collecting data from 262 consumers, we perform a confirmatory factor analysis to evaluate scale reliability and construct validity for the fashion readiness scale. Nomological validity for our scale is also verified. Therefore, the fashion readiness scale developed in this study is psychometrically sound, and it contains 12 items belonging to four subfactors, including fashion efficacy, fashion anxiety, fashion involvement, and fashion innovativeness. We believe that the fashion readiness scale will contribute greatly to current fashion research and practice.
\end{abstract}

C.-C. Hsiao $(\bowtie)$

Shih Hsin University, Taipei, Taiwan

e-mail: cchsiao@cc.shu.edu.tw

F.-M. Liu

Institute for Information Industry, Taipei, Taiwan

e-mail: julialiu@iii.org.tw

L. Petruzzellis, R.S. Winer (eds.), Rediscovering the Essentiality of Marketing, Developments in Marketing Science: Proceedings of the Academy of Marketing Science, DOI 10.1007/978-3-319-29877-1_106 